\title{
Restoration, archiving, and digitalization of the Museum collections (The case of Zoological Collections, Georgian National Museum)
}

\author{
Vera Pkhakadze ${ }^{1}$, Vakhtang Tsintsadze ${ }^{1}$, Medea Tsotselia ${ }^{1}$, Nataly Snegovaya ${ }^{2}$, \\ Nino Giorgobiani ${ }^{1}$, Maia Intskirveli ${ }^{1}$, Alisa Datunashvili ${ }^{1}$, \\ Nino Datunashvili ${ }^{1}$, Zurab Tvalchrelidze ${ }^{1,3}$, Salome Svanadze ${ }^{1}$
}

\author{
${ }^{1}$ Georgian National Museum; E-mail:vpkhakadze@museum.ge, vaxtangitsintsadze@gmail.com, \\ tsotselia@yahoo.com,giorgobianinino@gmail.com, maia.inckirveli@mail.ru, adatunashvili@gmail.com, \\ nino.museum@gmail.com, chantladzes@gmail.com \\ ${ }^{2}$ Institute of Zoology, Azerbaijan, Baku; snegovaya@yahoo.com \\ ${ }^{3}$ Medieval Research institute, E-mail: ztvalchrelidze@gmail.com
}

Received: 12.08.2019. Accepted: 26.09.2019

\begin{abstract}
The paper presents a pilot case of scientific revision and inventory process in the zoological collection of the Georgian National Museum (Tbilisi). By the special decree of the President of Georgia, the Georgian National Museum was established in 2004. Unifying fifteen museums, the National Gallery and two scientific centers it is the largest museum complex in the country. Its zoological collection is one of the oldest in Caucasia. Among them are endemic, relict, and other rare species protected by international conventions, and many are listed as endangered or deleted species in Georgia. Considering their importance, age and overall condition of the objects and documentation the reorganization of zoological collections was started as a pilot case in rehabilitation and cataloguing of GNM collections. Complete collections of Arachnidae (Opiliones) were studied and organized; Species of the family of Trogulidae, Nemastomatidae, Sclerosomatidae, Phalangiidae, order Harvestmen (Opiliones) from the class Arachnida, have been identified. There were in total 31 Harvestmen species from 4 families (Trogulidae, Nemastomatidae, Sclerosomatidae, and Phalangiidae) identified. One species of which - Odiellus zacariensis Mkheidze, 1952, is new for Azerbaijan fauna and four species: Trogulus rossicus Silhavy, 1968, Opilio sy/vestris Snegovaya 2010, Opilio caucasicus Snegovaya 2010, Opilio nabozhenkoi Snegovaya 2010 are new for the fauna of Georgia. Also two new species: Rilaena kelbajarica Snegovaya et Pkhakadze, 2014 and Phalangium mcheidzeae, Snegovaya, 2014 [5-6] have been described. Museums today aim to become a platform for developing and spreading scientific knowledge. Based on different collections: art, anthropology, archaeology, natural history etc. they become unique catalysers for interdisciplinary studies. Object-based scientific collections can open new areas of research across different disciplines. In this regard management of museum collections, information about them and making it accessible for scholars of different research fields and countries is a main task for a modern museum. Therefore, it is crucial to systematize the objects and collections, create new knowledge in collaboration with the academia and museum professionals internationally and promote the scientific knowledge for broader audience. The outcomes of the study will enhance the process of integration of GNM collections in international museum system and academia.
\end{abstract}

Key words: Museum; Collection; Zoology; Digitalization; Taxonomy; Revision

\section{Introduction}

Museums are cultural productions of the social, political and historical contexts in which they are produced. 'They do not arise 'just like that' but are politically, culturally, historically shaped and charged.' (Pieper 2010: 200). Being heir of Musaeum of Alexandria, medieval monastery treasuries, private galleries and cabinet museums have been changed drastically. "The modern museum is a product of Renaissance humanism, eighteens century enlightenment and nineteenth century democracy" (Alexander 1996:8)

In the Middle Ages special "treasuries" were founded in Georgian kings' palaces. There were rare samples of natural history, important historical objects, memorial materials of outstanding personalities and valuables collected. In the churches and monasteries also were functioning "treasuries". Precious samples of Georgian cultural heritage were collected in Georgian monasteries abroad: in the Monastery of Cross (Jerusalem), Mount Sinai and the Black Mountain (Sumela), Mount Athos, Petritsoni Monastery (Bachkovo) etc.

In the document presented by Ioane Batonishvili (Georgian public figure, encyclopedist, writer, and lexicographer) to his father, King George XII, the prince developed reformation concept of the kingdom of Kartl-Kakheti. In this document, known as "Sjuldeba" (1799), prince Ioane introduces also the idea of organizing library as storage of books and "other arts" (Bagrationi 1957:17).

Prince Teimuraz (1782 - 1846 a scholar primarily known as an author of the first critical history in Georgian as well as for his work to popularize interest in the history and culture of Georgia and preserve its treasures), member of the Copenhagen Society of Antiquarians, also tried to establish a little archaeological-ethnographical museum in Georgia. (Babuadze 2012:20) 


\section{Methodology}

Under the Tsarist Russia (1801-1918), different groups of intellectuals were concerned with the idea of establishing a museum. The Caucasian Department of the Russian Royal Geographic Society's Museum was founded in Tbilisi in 1852. Its first collections consisted of Natural history and ethnographic artifacts from all over the Caucasia. In the same period, the group of Georgian intellectuals 'Tergdaleulebi', also known as founding fathers of modern Georgian nationalism established the Museum of Spreading Literacy Among Georgians based mainly on ethnographic collections. In the short period of its independence from Russia (19181921), government of the Democratic Republic of Georgia managed to establish two national museums: Museum of Georgia (1919), and National Art Gallery (1920).

Already under the Soviet rule, the Museum of Georgia has become the "State Museum" (1935). Ivane Javakhishvili, one of the founding fathers of the Tbilisi State University, Georgian historian and linguist whose voluminous works heavily influenced the modern scholarship of the history and culture of Georgia introduced the goals of the museum: "Any reasonable person understands easily how great an obligation the Museum will have from now on. For a fundamental, in-depth study of political, material and intellectual history, the broader public - and especially students - need museums where everyone can see the material remains that are the physical expression of the history they read...

The Museum of Georgia is a grand establishment. First - it has to portray past and modern culture and, to this end, collect artifacts and other materials to ensure a comprehensive, scientific study of Georgia. Second - it has a social obligation - to help the public and, especially, young students to enhance their knowledge of history. Third - the Museum of Georgia, as the highest-level scientific institution, should be conducting intensive scientific work."'- (Gamkrelidze, Babuadze 2014:12)

After gaining independence (1991), Georgia experienced two wars (South Ossetia 1991-92 and Abkhazia 1992-93) and a civil war in 1989-90. National institutions hardly functioned. At every level of the state authorities corruption was common practice. The big shift in Georgia's recent history is so called "Rose" revolution of 2003: the non-violent change of political power, followed by reforms. The new governmental program included neoliberal reforms, which affected the Georgian Constitution, police, tax and customs, privatization and education systems.

Problems occurring in the Georgia's museums at the one hand and urge of the new political elites to change the soviet narrative of the county's history at the other hand required museum reforms. By the special decree of the President of Georgia, the Georgian National Museum (Tbilisi) was established in 2004 and unified five largest and most important museums of the country: Simon Janashia Museum of Georgia, Shalva Amiranashvili Museum of Fine Arts, Giorgi Chitaia Museum of Folk Architecture and Life, Ioseb Grishashvili Tbilisi History Museum and Vani Museum-Preserve. It was considered the "beginning of structural, institutional and legislative reforms in country's cultural heritage management. Reforms include introducing of modern management practices; elaboration and establishment of museum politics and integrated administrative system; improvement of museum collections safety standards; increase of educational activities; collaboration between museums and academia" (quotation from the museum web page). Today, unifying fifteen museums, the National Gallery and two scientific centers it is the largest museum complex in the country.

\section{Discussion}

Nearly two million objects of Georgian and Caucasian natural and cultural heritage are kept in the museum. Its highlights include hominid remains from Dmanisi dated back to 1.8 million years; endemic, relict and rare specimens listed in international conventions and the Georgian Red book; masterpieces of goldsmithery and chasing from the second half of the $3^{\text {rd }}$ millennia to the late Middle Ages, unique cloisonné enamel collection including world's largest "Khakhuli Triptych of the Holy Virgin" (1125 - 1155), epigraphic monuments of Georgian, Aramaic, Greek, Jewish, Arabic scripts and Urartian cuneiform, collection of Qajar portraits as well as masterpieces of Georgian, Russian and European artists including Paolo Veneziano, Lucas Kranach the Elder, Niko Pirosmani, Lado Gudiashvili, Vasil Kandinsky. Ethnographic collection, one of the first of the museum, houses significant material on people living in Caucasia.

The newly established Georgian National Museum had to cope with almost two centuries old problems: Museums unified under GNM umbrella used to have different approaches and systems of registration and cataloguing objects during dozens of years. Collection management policies and instructions were often ignored or violated. Different museums were subordinated to different bodies, which often did not control collection registration and maintenance process. Employees were not familiar to modern technologies; there was not enough funding to buy new equipment.

To solve the complex problem GNM Collections Registration and Management Division started to develop a strategy involving museum curators from different fields: history, archaeology, anthropology, art history and natural history. New standards and policies for collection management are being developed. At the same time, the full register of museums' collections is being prepared.

Meanwhile the Georgian Ministry of Culture and Monuments Protection initiated project for development of digital museum database, which will be a full registry of all museum objects with public access.

In order to meet national and international standards of museum collection registration, there was also a need for revision of classification, taxonomy and grouping of objects in different collections.

According to the documents studied within the framework of this research, the "registered" history of the collections start from 1865 , when so called ethnographical, zoological, botanical, geological and archaeological 'scientific cabinets' were established. Their objects were given the status of 'exponent'.

From that time, the museum collections' registration and management system had a rather long way of development and in the 40 's of the $20^{\text {th }}$ century the first legislative base for the entire Soviet museums' collection management was prepared. There were 'main' and 'auxiliary' collections identified. In the 'auxiliary collection' were grouped the objects having purely scientific and less aesthetic importance.

As in every museum, each object in the GNM shall be registered when acquired. A unique access number was given to it and the basic information about its provenance, material, measures etc. were entered in the special catalogue. Then the object was given in the respectful department to an appropriate curator, which entered professional description in a so-called "discipline-specific catalogue". Objects and their discipline-specific catalogues were kept in closed room/rooms under the supervision of the curator. During inventory, catalogues were used to identify objects and check collection condition, identify any loss or damage. The abovementioned documents have had, and according to Georgian legislation, still have legal force for the museum and its controlling authorities to maintain control over the collections. There were special mandatory policies regulating maintenance of 
these documents, but museums unified under GNM umbrella used to have different approaches and systems of registration and cataloguing objects.

In spite of the above described policies on collection management and registration, they were ignored or violated during dozens of years. Different museums were subordinated to different bodies which often did not control collection registration and maintenance process. Moreover, different museums used to have different approaches and systems of registration and cataloguing objects, which would change upon decision of their controlling body.

As an heir of the Caucasian Museum, the Georgian State Museum (today Simon Janashia Museum of Georgia) was under the governance of the Georgian Academy of Science from the $30^{\prime} \mathrm{s}$ of the $20^{\text {th }}$ century. Giving priority to the scientific research, less attention was paid to museum management and registration system.

From 2004, the Simon Janashia Museum became part of the Georgian National Museum and thus, separated from the Academy of Science. From that point on, registration, digitalization and popularization of collections became an agenda.

As mentioned above, the history of the collections of the Georgian National Museum began in the $19^{\text {th }}$ century. The first collections were acquired by the German naturalist and the first director of the Caucasian Museum Gustav Radde (the first registered zoological exponent dates 1866, Panthera tigris virgate is still kept in the museum).

The collections have been enriched over the years by materials from expeditions within the Caucasus and from other countries or from organizations, as well as private donations, exchanges and purchases.

Many generations have contributed to establishing and replenishing the Natural Historic collections. Thanks to those scientists (G. Radde, F. Bayern, T. Lorenz, K. Koch, G. Woronov, A. Shelkovnikov, A. Satunin, E. Coenig, M. Mlokosievich, A. Kaznakov, K. Rostombekov, I. Voronov, R. Schmidt etc.), the significant species inhabiting territory of the Caucasus are kept in museum depositories. It is rich on invertebrates and vertebrates: Plathelminthes, Nemertini, Nemathelminthes, Acanthocephales, Annelides, Mollusca, Arthropoda, Bryozoa, Brachipoda, Echinodermata, Pogonophora, Hemichordata, Chaetognatha, and Chordata. Among them are endemic, relict and other rare species protected by international conventions, and many are listed as endangered or deleted species in Georgia (Bison bonasus caucasicus, Panthera tigris virgata).

In terms of their opulence, content and uniqueness, the natural history collections of the Georgian National Museum are of high significance not only at national or regional but also at international level.

In the framework of the project "Rehabilitation and Cataloguing of the Inventory Documentation of the Georgian National Museum Collections (Funds)" (funded by the Shota Rustaveli national scientific foundation of Georgia) during 2016-2019 all catalogues including discipline-specific journals of the entire Georgian National Museums were photographed and studied.

Considering their importance, age and overall condition of the objects and documentation the reorganization of zoological collections was started as a pilot case in rehabilitation and cataloguing of GNM collections. Complete collections of Arachnidae (Opiliones) were studied and organized.

At the very beginning of the project the need for the new inventory numbers became obvious: some objects were not registered in the main museum catalogue, some numbers were impossible to identify, some objects were catalogued differently as other collections of the museum and some were given two different inventory numbers: 1 . Number from the main museum catalogue; 2 . Number from the discipline-specific journal.

Formula for the inventory number of the Georgian National Museum objects was developed as follows: GNM0-0-0000/0, where GNM an abbreviation of the Georgian National Museum, following digit indicates the museum (e.g. 1 is for Janashia Museum), next digit is collection number, following four digits refer to the year acquired the object and the last one, after the slash is for the quantity of the object/s. For example, specimens from Arachnidae collection is GNM1-4-2001/1 (Rilaena kelbajarica Snegovaya et Pkhakadze, 2014) and GNM1-4-2001/2 (Phalangium mcheidzeae, Snegovaya, 2014).

The inventory number formulated in this way will never repeat: Collections are organized according to ascending years and easily arranged and accessed by collection number and acquisition year. Exponents have only one number, which can be traced in every document and catalogue/publication.

Entering the museum, the newly acquired example of fauna is registered and given the unique inventory number. In the main museum catalogue the primary information: acquisition, material/type of object, sizes, etc. are recorded. On the next stage, the object is sent to a corresponding department, where a curator describes it scientifically. The material, which has a pure scientific significance, is sent to the scientific-auxiliary collection. Such objects will be used as a material for genetic researches and/or sent to the "exchange collection" (excess duplicates for the exchange with other institutions).

As for the old collections, the following activities are carried out: each collection/object is checked and all the information is compared from the main catalogue and discipline-specific journal; the information is scientifically revised and corrections in inventory catalogues made accordingly; additional entries are made and missing information added; restoration-conservation works are carried out.

At the same time, the priorities of the department are identified and special inventory card for each collection/object is being developed.

The works carried out already have improved not only an overall workflow and research quality within the department, but enhanced our accessibility and integration in the international museum society and academia.

As a result of our study of spineless and vertebral animals collection of the Georgian National Museum, species of the family of Trogulidae, Nemastomatidae, Sclerosomatidae, Phalangiidae, order Harvestmen (Opiliones) from the class Arachnida, have been identified; their scientific revision, inventory and restoration were carried out. In the depository the collections are arranged/organized based on their scientific taxonomy order: family/genus/species according to international scientific and museum standards.

Technological process was carried out according to the acknowledged standards of the field, preparation and scientific research.

Every kind of information available in the museum/department was carefully studied: old etiquettes, records, photographs (old etiquettes are still kept in the department).

There were in total 31 Harvestmen species from 4 families (Trogulidae, Nemastomatidae, Sclerosomatidae, and Phalangiidae) identified. One species of which - Odiellus zacariensis Mkheidze, 1952, is new for Azerbaijan fauna and four species: Trogulus rossicus Silhavy, 1968, Opilio sy/vestris Snegovaya 2010, Opilio caucasicus Snegovaya 2010, Opilio nabozhenkoi Snegovaya 2010 are new for the fauna of Georgia. Also two new species: Rilaena kelbajarica Snegovaya et Pkhakadze, 2014 and Phalangium mcheidzeae, Snegovaya, 2014 [5-6] have been described. 
As an outcome of our project, formula for inventory number of the Georgian National Museum was approved by the Ministry of Georgian Culture, Education and Sport and is being used after the approval of the General Director of the Georgian National Museum since January 1, 2018.

After recommendations of the project participants elaborated standard for the museum inventory catalogues (main as well as discipline-specific) was published which is been in use since 2018 not only for zoological, but for all museum collections. Improved form of object etiquettes were worked out.

Strategy and Recommendations for further works to be cared out were developed. Taking into consideration errors in documents, implementation of new inventory numbers and collection management policies and new research data, old journals shall be archived. As soon as the inventory process will be finished, only new catalogues shall be used in the National Museum.

Nationwide policy of museum collections' registration and protection is regulated with the "Instruction for Registration and Protection of Museum valuables" approved by the Ministry of Culture and Monuments' Protection in 2010. Taking into consideration the experience from re-inventory of zoological collections, the team of the GNM is involved in development of the improved version of this document, which will be issued at the end of this year.

Contemporary western museums became not only bearers of certain discourses of different elites, but educational institutions accessible for every citizen. Museum is the place for spreading and sharing scientific knowledge, platform for communication with, between and among societies. To accomplish this task it is crucial to organize the knowledge about the objects and collections. Therefore, modern museums create and constantly improve data bases about the objects to make them comprehensive and accessible.

Modern technological approaches are the new challenge for the museums all over the world and especially in the post-soviet states. The century-old static expositions and narratives interpreted according to soviet ideology are changing with introduction of new research methods and the influence by modern social theories.

\section{Conclusion}

To meet new challenges knowledge about the objects and collections shall be organized. A museum object is not only a material object but first of all, bearer of the information, which gives meaning to it and thus - the value. For contemporary museums, having collection is a means but not an end. Creating genuine experience through objects and collections using modern technologies is the goal of modern museum. Learning through experience is the end of modern museums (Hein 2000)

Moreover, museums today aim to become a platform for developing and spreading scientific knowledge. Based on different collections: art, anthropology, archaeology, natural history etc. - they become unique catalysers for interdisciplinary studies. Objectbased scientific collections can open new areas of research across different disciplines. In this regard management of museum collections, information about them and making it accessible for scholars of different research fields and countries is a main task for a modern museum. The task of the Georgian National Museum is not just to preserve these unique collections but to study and to provide their public access. Therefore, it is crucial to systematize the objects and collections, create new knowledge in collaboration with the academia and museum professionals internationally and promote the scientific knowledge for broader audience.

\section{Acknowledgements}

The paper was prepared in the framework of Shota Rustaveli Science Foundation funded project "Rehabilitation and Cataloguing of Museum Collections (Funds) Registration Catalogues" (Project Code 217978, Grant Agreement No217978/09.12.2016).

\section{References}

Alexander, E. P. (1996). Museums in Motion. Alatmyra Press, A division of Rowman and Littlefield Publishers, Walnut Creek. Bagrationi, I. (1957). Sjuldeba, Stalinis saxelobis tbilisis saxelmtsifo universitetis gamomtsemloba. Tbilisi (in Georgian).

Gamkrelidze, E, Babuadze, T. (2014). Roots of the Georgian National Museum. Museum, Georgian National Museum, Tbilisi. Chilashvili, L. (2002). Looking Back 150 Years, Museum Anniversary, 29-71pp, Bulletin, No 44.

Chkhaidze, G. (2003). The State Museum of Georgia' (1852-1932). Tbilisi.

Hein, H. S. (2000). The Museum in Transition. Washington: Smithsonian Books

Pieper, K. (2010). Resonanzräume: Das Museum im Forschungsfeld Erinnerungskultur, In Joachim Baur's (Ed): Museumsanalys. Methoden und Kontureeines neuen Forschungsfeldes, Bielefeld: Tranksript Verlag.

Jordania, G. (1951). Establishment of the Caucasus Museum. Tbilisi.

Snegovaya, N. Yu. (2014). Survey of the genus Phalangium Linnaeus, 1758 (Phalangiidae: Opiliones) from the Caucasus with description of two new species. Fragmenta Faunistica, 57(1), 1-19. DOI10.3161/00159301FF2014.57. 1.001

Snegovaya, N., Pkhakadze, V. (2014). New species of the genus Rilaena (Opiliones, Pphalangiidae) from Mount Gyamish, Azerbaijan. Bulletin Zoology, 48(4), 313-318, DOI 10.2478/vzoo-2014-0037, UDC 595.43.

Snegovaya, N., Pkhakadze, V., Intskirveli, M. (2014). Hervestmen (Arachnida, Opiliones) From the Collection of the National Museum of Georgia. Proceedings of the Azerbaijan Institute of Zoology, 32(1), 198-207.

\section{Citation:}

V. Pkhakadze, V. Tsintsadze, M. Tsotselia, N. Snegovaya, N. Giorgobiani, M. Intskirveli, A. Datunashvili, N. Datunashvili, Z. Tvalchrelidze, S. Svanadze (2019). Restoration, Archiving, and Digitalization of the Museum Collections (The case of Zoological Collections, Georgian National Museum). Ukrainian Journal of Ecology, 9(3), 138-141.

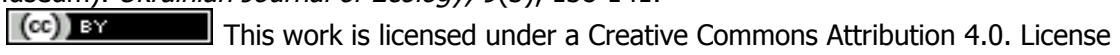

